\title{
A STUDY OF LIPID PROFILE IN NON-INSULIN DEPENDED DIABETES MELLITUS
}

KEY WORDS: Diabetes mellitus \& Lipid profile

\section{Dr Ketan}

Prajapati*

Dr Ravi Surani

Dr Samirdan

Tapariya

\section{Dr M J Sonagara}

\section{Dr U S Gediya}

Resident, Department of General Medicine, C. U. Shah Medical College, Surendranagar, Gujarat *Corresponding Author

Resident, Department of General Medicine, C. U. Shah Medical College, Surendranagar, Gujarat

Assi.Professor, Department of General Medicine, C. U. Shah Medical College, Surendranagar, Gujarat

Professor, Department of General Medicine, C. U .Shah Medical College, Surendranagar, Gujarat

Professor, Department of General Medicine, C. U. Shah Medical College, Surendranagar, Gujarat

Introduction: Diabetes mellitus (DM) refers to a group of common metabolic disorders that share the phenotype of hyperglycaemia. Several distinct types of DM are caused by a complex interaction of genetics and environmental factors. Depending on the aetiology of the DM, factors contributing to hyperglycaemia include reduced insulin secretion, decreased glucose utilization, and increased glucose production. The metabolic dysregulation associated with DM causes secondary pathophysiologic changes in multiple organ systems that impose a tremendous burden on the individual with diabetes and on the health care system. In India, DM is the leading cause of end-stage renal disease (ESRD), nontraumatic lower extremity amputations, and adult blindness. It also predisposes to cardiovascular diseases. With an increasing incidence worldwide, DM will be likely a leading cause of morbidity and mortality in the future. Methodology: This study conducted in medicine Dept. of C U Shah medical college, Surendranagar on patients (selected on basis of inclusion and exclusion criteria's). This study conducted between February 2018 to September 2019. This study was done after approval of THE INSTITUTIONAL ETHICS COMMITTEE (HUMAN RESEARCH) of C U Shah medical college, Surendranagar.

Result: There is significant correlation between triglyceride level and diabetes mellitus. $60 \%$ of diabetic patients have more than optimal levels.

Conclusion: Dyslipidemia are highly prevalent in diabetic patients particularly more in poorly controlled diabetes.Lipid profile should be done annually in all diabetic patient. Out of 100 patients 34 have high LDL/HDL ratio which was proved statistically significant.

\section{INTRODUCTION}

Diabetes mellitus (DM) refers to a group of common metabolic disorders that share the phenotype of hyperglycemia. Several distinct types of DM are caused by a complex interaction of genetics and environmental factors. Depending on the etiology of the DM, factors contributing to hyperglycemia include reduced insulin secretion, decreased glucose utilization, and increased glucose production. The metabolic dysregulation associated with DM causes secondary pathophysiologic changes in multiple organ systems that impose a tremendous burden on the individual with diabetes and on the health care system. In India, DM is the leading cause of end-stage renal disease (ESRD), nontraumatic lower extremity amputations, and adult blindness. It also predisposes to cardiovascular diseases. With an increasing incidence worldwide, DM will be likely a leading cause of morbidity and mortality in the future. ${ }^{(1,2)}$

The worldwide prevalence of DM has risen dramatically over the past two decades, from an estimated 30 million cases in 1985 to 382 million in 2013. Based on current trends, the International Diabetes Federation projects that 592 million individuals will have diabetes by the year2035. Although the prevalence of both type 1 and type $2 \mathrm{DM}$ is increasing worldwide, the prevalence of type $2 \mathrm{DM}$ is rising much more rapidly, presumably because of increasing obesity, reduced activity levels as countries become more industrialized, and the aging of the population. In 2013, the prevalence of diabetes in individuals from age 20-79 ranged from 23 to $37 \%$ in the 10 countries with the highest prevalence.

The countries with the greatest number of individuals with diabetes in 2013 are China (98.4million), India (65.1 million), United States (24.4 million), Brazil (11.9 million), and the Russian Federation (10.9 million). Up to $80 \%$ of individuals with diabetes live in low-income or medium-income countries. ${ }^{(3,4)}$

The CDC estimated that the incidence and prevalence of diabetes doubled from 1990-2008, but appears to have plateaued from 2008-2012.DM increases with age.

Diabetic patients have a greater likelihood of having dyslipidemia, hypertension, and obesity. Because early detection and prompt treatment may reduce the burden of diabetes and its complications, screening for diabetes may be appropriate under certain circumstances. Epidemi ological studies have demonstrated that type 2 diabetes mellitus (DM) is a well-known risk factor for the development of cardiovascular disease, cerebrovascular disease and peripheral vascular diseases. Dyslipidemia is a risk factor for coronary artery disease, a leading cause of mortality in patients with diabetes mellitus. Dyslipidemia remains largely undiagnosed and under treated in high risk populations, such as patient with type- 2 diabetes. ${ }^{(5,6)}$

A characteristic pattern, termed diabetic dyslipidemia, consists of specifically mild to marked elevation of triglyceride-rich lipoproteins (VLDLs) and VLDL remnants concentrations and low levels of HDL-C. Raised serum triglycerides and low HDL-C often precede the onset of T2DM for many years. In addition, LDL particles are converted to smaller, perhaps more atherogenic, lipoproteins termed 'small-dense LDLs'. Different mechanisms are responsible for

November, $2019 \quad$ Publication : $15^{\text {th }}$ December, 2019 
the development of dyslipidemia in individuals with diabetes. Defects in insulin action and hyperglycemia could lead to dyslipidemia in patients with diabetes. In the case of T2DM, the obesity/insulinresistant state that is at the basis of the development of this disease can in itself lead to lipid abnormalities independently of hyperglycemia. In poorly controlled TIDM hypertriglyceridemia and reduced HDL-C commonly occur, but in most cases insulin replacement in these patients correct these abnormalities. In T2DM, this phenotype is not usually fully corrected with glycemic control, suggesting that insulin resistance and not hyperglycemia per se are associated with this lipid abnormality. Insulin-controlled apoprotein production in the liver, regulation of lipoprotein lipase (LPL), actions of cholesteryl ester transfer protein (CETP) and peripheral actions of insulin on adipose tissue and muscles are considered to be important mechanisms responsible for diabetic dyslipidemia. ${ }^{(7)}$

\section{METHODOLOGY}

This study conducted in medicine Dept. of C U Shah medical college, Surendranagar on patients (selected on basis of inclusion and exclusion criteria's). This study conducted between February 2018 to September 2019. This study was done after approval of THE INSTITUTIONAL ETHICS COMMITTEE (HUMAN RESEARCH) of C U Shah medical college, Surendranagar. A cross sectional study of 100 type 2 diabetic patients. The participants were already diagnosed as type 2 diabetics and undergoing treatment.

A written informed consent form was completed by all the participants who were recruited into the study. The purpose of the study was explained to the participants in English and local language as they understand. Detail history and physical examinations was conducted.

Information on clinical features and anthropometric measurements were taken.

Following investigation was done;

Complete hemogram including Total count, platelet count, Hemoglobin S.creatinine, S.electolytes, Urine routine microbiological examination, Fasting blood sugar and postprandial Blood sugar, HbA IC, S.TSH, Lipid profile.

\section{RESULTS}

Table 1: Age \& Sex wise distributions

\begin{tabular}{|l|l|l|}
\hline \multirow{2}{*}{ AGE } & \multicolumn{2}{|c|}{ NUMBER OF PATIENTS } \\
\cline { 2 - 3 } & \multicolumn{1}{|c|}{ MALE } & \multicolumn{1}{c|}{ FEMALE } \\
\hline $30-40$ & 11 & 5 \\
\hline $41-50$ & 11 & 13 \\
\hline $51-60$ & 16 & 19 \\
\hline $61-70$ & 9 & 7 \\
\hline $71-80$ & 5 & 2 \\
\hline $81-90$ & 0 & 2 \\
\hline
\end{tabular}

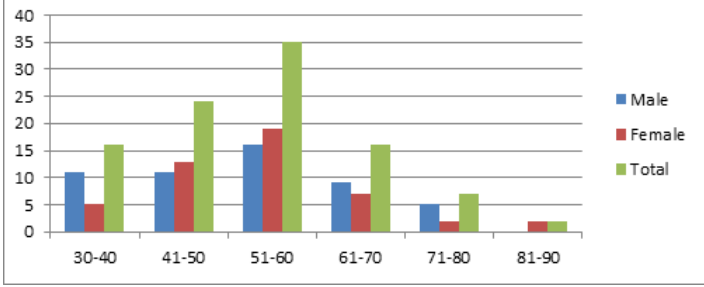

In this study most common affected age group are 51 to 60year (35\%) followed by 41 to50 (24\%)

Table 2: Clinical feature

\begin{tabular}{|l|l|l|}
\hline CLINICAL FEATURES & \multicolumn{2}{|l|}{ NUMBER OF PATIENTS } \\
\cline { 2 - 3 } & MALE & FEMALE \\
\hline POLYUREA & 11 & 10 \\
\hline
\end{tabular}

\begin{tabular}{|l|l|l|}
\hline POLYPHAGIA & 7 & 4 \\
\hline POLYDYPSIA & 2 & 7 \\
\hline TINGLING \& NUMBNESS & 13 & 12 \\
\hline SLOW HEALING ULCER & 5 & 4 \\
\hline FREQUENT INFECTION & 11 & 5 \\
\hline BLURRING OF VISION & 7 & 5 \\
\hline
\end{tabular}

In present study Tingling \& numbness is most common clinical symptom followed by polyurea.

Table: 3 S.CHOLESTROL

\begin{tabular}{|l|l|l|}
\hline \multirow{2}{*}{$\begin{array}{l}\text { CHOLESTROL } \\
\text { (mg) }\end{array}$} & \multicolumn{2}{|l|}{ NUMBER OF PATIENTS } \\
\cline { 2 - 3 } & MALE & FEMALE \\
\hline$<160$ (optimal) & 15 & 14 \\
\hline $160-199$ (near or above optimal) & 17 & 10 \\
\hline $200-239$ (borderline) & 4 & 5 \\
\hline $240-279$ (high) & 11 & 10 \\
\hline$>280$ (above high) & 5 & 9 \\
\hline
\end{tabular}

This table is showing distributions of S.CHOLESTROL in type 2 diabetes mellitus patients.

In my study around 21 patients ( 11 male and 10 female ) having s.cholestrol between $240-279$ (HIGH) and 14 patients ( 5 male and 9 female ) having s.cholestrol more than 280 ( ABOVE HIGH)

Table 4: S.TRIGLYCERIDE

\begin{tabular}{|l|l|l|}
\hline \multirow{2}{*}{$\begin{array}{l}\text { TRIGLYCERIDE } \\
\text { (mg/dL) }\end{array}$} & \multicolumn{2}{|l|}{ NUMBER OF PATIENTS } \\
\cline { 2 - 3 } & MALE & FEMALE \\
\hline$<150$ (optimal) & 23 & 17 \\
\hline $150-169$ (near or above optimal) & 9 & 14 \\
\hline $170-199$ (borderline) & 7 & 7 \\
\hline $200-499$ (high) & 12 & 10 \\
\hline$>500$ (above high) & 1 & 0 \\
\hline
\end{tabular}

This table is showing distributions of S.TRYGLYCERIDE in type 2 diabetes mellitus patients.

In my study around 22 patients ( 12 male and 10 fmale ) have s.tryglyceride level between $200-499 \mathrm{mg} / \mathrm{dL}$ ( $\mathrm{HIGH}$ ) and 1 male patients having s.tryglyceride level more than 500 $\mathrm{mg} / \mathrm{dL}$.

\section{Table 5: S.HDL}

\begin{tabular}{|l|l|l|}
\hline \multirow{2}{*}{$\begin{array}{l}\text { HDL } \\
\text { (mg/dL) }\end{array}$} & \multicolumn{2}{|l|}{ NUMBER OF PATIENTS } \\
\cline { 2 - 3 } & MALE & FEMALE \\
\hline$<40$ (low) & 33 & 31 \\
\hline $40-49$ (borderline) & 11 & 9 \\
\hline $50-59$ near or below optimal) & 5 & 4 \\
\hline$>60$ ( optimal) & 3 & 4 \\
\hline
\end{tabular}

This table is showing distributions of S.HDL in type 2 diabetes mellitus patients.

In my study around 20 patients ( 11 male and 9 female) having S.HDL level between 40-49 $\mathrm{mg} / \mathrm{dL}$ (BORDERLINE) and 64 patients ( 33 male and 31 female ) having S.HDL level below 40 $\mathrm{mg} / \mathrm{dL}$ (LOW).

\section{Table 6:S.LDL}

\begin{tabular}{|l|l|l|}
\hline \multirow{2}{*}{$\begin{array}{l}\text { LDL } \\
(\mathrm{mg} / \mathrm{dL})\end{array}$} & \multicolumn{2}{|l|}{ NUMBER OF PATIENTS } \\
\cline { 2 - 3 } & MALE & FEMALE \\
\hline$<100$ (optimal) & 21 & 20 \\
\hline $100-129$ (near or above optimal) & 14 & 14 \\
\hline $130-159$ (borderline) & 10 & 6 \\
\hline $160-189$ (high) & 5 & 6 \\
\hline$>190$ (very high) & 2 & 2 \\
\hline
\end{tabular}

This table is showing distributions of S.CHOLESTROL in type 2 diabetes mellitus patients. 
In my study around 17 patients ( 10 male and 6 fmale ) have S.LDL level between 130-159 mg/dL ( BORDERLINE ) , 11 patients ( 5 male and 6 female) having S.LDL between 160-189 $\mathrm{mg} / \mathrm{dL}(\mathrm{HIGH})$ and 4 patients ( 2 male and 2 female ) having S.LDL more than $190 \mathrm{mg} / \mathrm{dL}$ (VERY HIGH).

Table 7: LDL/HDL RATIO

\begin{tabular}{|l|l|l|}
\hline \multirow{2}{*}{ LDL/HDL RATIO } & NUMBER OF PATIENTS \\
\cline { 2 - 3 } & MALE & FEMALE \\
\hline$<1.6$ (optimal) & 3 & 3 \\
\hline $1.6-2.7$ (near borderline) & 17 & 18 \\
\hline $2.7-3.7$ (borderline) & 15 & 10 \\
\hline $3.7-4.7$ (high) & 9 & 6 \\
\hline$>4.7$ (v. high) & 8 & 11 \\
\hline
\end{tabular}

This table showing distribution of patients according to LDL/HDL ratio.

In my study around 25 patients ( 15 male and 10 female ) have LDL/HDL ratio between 2.7-3.7 (borderline).

15 patients ( 9 male and 6 female ) have LDL/HDL ratio between 3.7-4.7 (high).

19 patients ( 8 male and 11 female ) have LDL/HDL ratio above 4.7 (v.high).

\section{DISCUSSION}

There is significant correlation between triglyceride level and diabetes mellitus. $60 \%$ of diabetic patients have more than optimal levels which is similar to Ghat of Haffner s m, K \& Lassko M study . There is $64 \%$ patients have S.HDL level less than optimal which is similar to Ronnemaa T, study on relation between lipids and diabetes ${ }^{(8)} 32 \%$ of study group patients have S.LDL levels more than optimal range with $11 \%$ with high level which similar to Lehto S., Pyorala $\mathrm{K}$ study on relation between lipids and diabetes. Out of 100 patients 34 have high $\mathrm{LDL} / \mathrm{HDL}$ ratio which was proved statistically significant. This study showed similar results to to Lehto S., Pyorala K study on relation between lipids and diabetes. ${ }^{(8)}$

\section{CONCUSION}

The present study highlights the magnitude of dyslipidemia in type 2 diabetes mellitus patients and that there is a significant association of TYPE 2 diabetes mellitus. Dyslipidemia are highly prevalent in diabetic patients particularly more in poorly controlled diabetes. This is mostly seen in patient having high calorie diet, physical inactivity, high stress level and habit od smoking and alcohol. Lipid profile should be done annually in all diabetic patients.

\section{REFERENCES}

1. American Diabetes Association. (2003) Diabetes Care, Volume 26, Supplement

2. Bruce D.G., Chisholm D.J., Storlien L.H. and Kraegen EW. (1988) Physiological importance of deficiency in early prandial insulin secretion in non-insulindependent diabetes.Diabetes;37:736-744.

3. Boon A. N. (2006) Davidson's Principles and Practice of Medicine. 20th Edition. USA. Churchill Livingstone.

4. Boyle P.J. (2007) Diabetes mellitus and macrovascular disease: mechanisms and mediators. Am J Med 120:S12-S17,2007.

5. Benedict C., Scheller J., Rose-John S., Born J. and Marshall L. (2009) Enhancing influence of intranasal interleukin- 6 on slow-wave activity and memory consolidation during sleep. FASEB J.23(10),3629-3636.

6. Del Pilar Solano M. and Goldberg R.B. (2005) Management of diabetic dyslipidemia. Endocrinol Metab Clin North Am 34: 1-25

7. Durrington P. and Sniderman A. (2002) Secondary hyperlipidemia. In: Hyperlipidemia. Durrington P, Sniderman A (Eds). Health Press, Oxford, UK, 71-89.

8. Haffner S.M., Lehto S., Ronnemaa T., Pyorala K. and Laasko M. (1998) Mortality from coronary heart diasease in subjects with type 2 diabetes and in nondiabetics subjects with and without prior myocardial infarction. N Eng J Med;339:229-34. 